\title{
ANALISIS KELAYAKAN AGROWISATA \\ (Studi Kasus pada Ghitari Coffee Plantation di Lembang Kaero Kecamatan Sangalla' Kabupaten Tana Toraja, Provinsi Sulawesi Selatan) \\ FEASIBILITY ANALYSIS OF AGROTOURISM \\ (Case Study at the Ghitari Coffee Plantation in Lembang Kaero, District Sangalla', TanaToraja of South Sulawesi)
}

\author{
Astuti Siama*, Nurdin Lanuhu, Pipi Diansari, Didi Rukmana, Saadah \\ Program Studi Agribisnis, Departemen Sosial Ekonomi Pertanian, \\ Fakultas Pertanian, Universita Hasanuddin, Makassar \\ astutisiama031@gmail.com
}

\begin{abstract}
The development of coffee plantation land has become an important tourism area in the preservation of agricultural land resources. This study aims to analyze the feasibility of developing agro-tourism in the Ghitari Coffee Plantation in terms of three aspects, namely the biophysical, economic and socioculture aspects, where if the three aspects are fulfilled then the business is considered feasible to be carried out. This research was carried out at the Ghitari Coffee Plantation, located in Lembang Kaero, Sangalla' District, Tana Toraja, South Sulawesi. The analytical method used is qualitative and quantitative analysis, where the qualitative analysis is used to analyze the feasibility of biophysical and socio-cultural aspects, while the quantitative analysis is used to analyze economic aspects using the NPV and IRR methods. The results showed that the aspect studied, both from the biophysical, economic and socio-cultural aspect were fulfilled. Based on the results of the calculation of IRR and $N P V$, the result of $P V$ of Proceeds is $R p .789,992,946$ and $P V$ of Outlays of $R p .620,000,000$, so the $N P V$ value is positive, in the amount of Rp. 169,992,946. While the IRR calculation result is $27 \%$, so it is considered feasible because the IRR value is greater than the interest rate.
\end{abstract}

Keywords: Business Feasibility Analysis, Coffee Plantation, Agro Tourism.

\begin{abstract}
Abstrak
Pengembangan lahan perkebunan kopi menjadi kawasan pariwisata merupakan bagian dari agribisnis yang berperan penting dalam pelestarian sumber daya lahan pertanian. Penelitian ini bertujuan untuk menganalisis kelayakan mengenai pengembangan agrowisata pada Ghitari Coffee Plantation yang ditinjau dari tiga aspek yaitu aspek biofisik, aspek ekonomi dan aspek sosial budaya, dimana apabila ketiga aspek tersebut terpenuhi maka usaha dinilai layak untuk dilaksanakan. Penelitian ini dilaksanakan di Ghitari Coffee Plantation yang berlokasi di Lembang Kaero, Kecamatan Sangalla', Kabupaten Tana Toraja Provinsi Sulawesi Selatan. Metode analisis yang digunakan yaitu analisis kualitatif dan kuantitatif, dimana analisis kualitatif digunakan untuk menganalisis kelayakan dari aspek biofisik dan aspek sosial budaya, sedangkan analisis kuantitatif digunakan untuk menganalisis aspek ekonomi dengan menggunakan metode NPV dan IRR. Hasil penelitian menunjukkan bahwa aspekaspek yang diteliti baik dari aspek biofisik, aspek ekonomi maupun aspek sosial budaya telah terpenuhi. Berdasarkan hasil perhitungan IRR dan NPV, didapatkan hasil PV of Proceeds sebesar Rp. 789.992.946,- dan PV of Outlays sebesar Rp. 620.000.000,- sehingga didapatkan nilai NPV-nya positif yaitu sebesar Rp. 169.992.946,-. Sedangkan berdasarkan hasil perhitungan IRR didapatkan sebesar $27 \%$ sehingga dinyatakan layak karena nilai IRR lebih besar dibandingkan interest ratenya.
\end{abstract}

Kata Kunci: $\quad$ Analisis Kelayakan Bisnis, Perkebunan Kopi, Agrowisata 
Sitasi: Astuti Siama*, Nurdin Lanuhu, Pipi Diansari, Didi Rukmana, Saadah 2020. Analisis Kelayakan Agrowisata. (Studi Kasus pada Ghitari Coffee Plantation di Lembang Kaero Kecamatan Sangalla' Kabupaten Tana Toraja, Provinsi Sulawesi Selatan). JSEP 16(2): 149 - 160.

\section{Pendahuluan}

Salah satu komoditas tanaman perkebunan yang banyak dibudidayakan adalah tanaman kopi. Kopi Indonesia saat ini menempati peringkat ketiga terbesar di dunia dari segi hasil produksi. Tanaman kopi sudah lama dibudidayakan baik oleh rakyat maupun perkebunan besar. Kopi menjadi begitu penting dalam kehidupan masyarakat Indonesia, terutama sejak banyaknya waralaba asal luar negeri yang menjual kopi (Narulita et al, 2014). Kopi sekarang tidak hanya dikonsumsi orangorang desa yang lebih dekat dengan komoditas biji kopi ini, tetapi juga menjadi konsumsi orang kota, dengan teknologi yang canggih (Marhaenanto et al, 2015). Namun keberhasilan agribisnis kopi di Indonesia membutuhkan dukungan semua pihak yang terkait dalam proses produksi kopi pengolahan dan pemasaran komoditas kopi. Upaya meningkatkan produktivitas dan mutu kopi terus dilakukan sehingga daya saing kopi di Indonesia dapat bersaing di pasar dunia (Kusmiati, 2015).

Komoditas kopi mempunyai prospek yang cukup cerah di masa mendatang, hal ini terutama dilihat dari prospek pasar yang cenderung meningkat sehingga memberikan peluang bagi Indonesia untuk meningkatkan pangsa pasar ekspor kopi baik jenis spesialti (biji kopi terbaik) maupun produk olahan kopi (Parnadi dan Loisa, 2018). Tanaman kopi di Indonesia ada berbagai jenis, namun sebagian besar ekspor kopi Indonesia adalah jenis kopi robusta dan jenis kopi arabika. Kopi arabika Indonesia sudah lama dikenal di pasar internasional dengan cita rasa terbaik di dunia, karena memiliki kekhususan dalam iklim mikro, varietas, dan pengolahan, produk. Kopi arabika Indonesia memiliki potensi sebagai kopi berkualitas tinggi (Kusmiati, 2015).

Sulawesi Selatan merupakan salah satu provinsi di Kawasan Timur Indonesia yang memiliki potensi pengembangan tanaman kopi. Hal ini ditunjukkan dengan areal penanaman yang cukup luas serta keadaan agroklimatologi yang sangat mendukung. Berdasarkan data Statistik Perkebunan Indonesia 2015-2017, Sulawesi Selatan memiliki luas areal perkebunan yakni 73.392 Ha dengan total produksi 30.992 ton. Perkebunan kopi yang ada di Sulawesi Selatan terdiri dari Perkebunan Rakyat dan Perkebunan Besar Swasta. Luas perkebunan Rakyat di Sulawesi Selatan adalah 71.396 Ha dengan total produksi yang tersebar di tiap kabupaten, sedangkan Perkebunan Besar Swasta hanya terdapat di Kabupaten Tana Toraja dengan luas 1.996 Ha dan total produksi 1.090 ton (Direktorat Jenderal Perkebunan, 2017).

Tana Toraja merupakan salah satu daerah penghasil kopi terbesar di Sulawesi Selatan. Berdasarkan data Statistik Perkebunan Indonesia, luas lahan kopi di Tana Toraja mencapai 12.782 Ha dengan total produksi 3.890 ton. Perkebunan kopi di Tana Toraja tersebar di 19 kecamatan yang terdiri dari perkebunan rakyat dan perkebunan swasta . Kecamatan Sangalla' merupakan salah satu kecamatan yang memiliki areal perkebunan kopi dengan luas lahan 216 Ha dan produksi 61,9 ton. Berdasarkan data yang diperoleh dari Badan Pusat Statistik (BPS) Kabupaten Tana 
Toraja, kopi merupakan tanaman perkebunan yang memiliki jumlah produksi terbesar di Kecamatan Sangalla'.

Selain sebagai sentra kopi, Tana Toraja merupakan daerah tujuan wisata. Dengan melihat potensi perkebunan kopi dan pariwisata di Tana Toraja, potensi tersebut dapat menjadi peluang untuk mengembangkan konsep agrowisata Tana Toraja dengan menggabungkan perkebunan kopi dan pariwisata. Agrowisata adalah aktivitas wisata yang melibatkan penggunaan lahan pertanian atau fasilitas terkait menjadi daya tarik bagi wisatawan dan sebaiknya berbasis pada partisipasi masyarakat sekitar lokasi pertanian tersebut (Makarim dan Baiquni, 2015; Salman, 2005). Peluang agrowisata cukup prospektif, karena selain sebagai salah satu penghasil pertumbuhan ekonomi juga berpeluang untuk dapat menjadi pendorong pertumbuhan sektor pembangunan lainnya, seperti sektor perkebunan, pertanian, perdagangan, perindustrian dan lain-lain. Potensi agrowisata tersebut berbasis pada keindahan alam pertanian dan produksi sektor pertanian yang cukup berkembang di Tana Toraja (Itamar, 2016).

Salah satu destinasi agrowisata di Tana Toraja adalah Ghitari Coffe Plantation, yang merupakan objek wisata unik dan klasik di Lembang Kaero, Kecamatan Sangalla', Kabupaten Tana Toraja. Tempat ini adalah perkebunan kopi arabika asli Toraja milik perseorangan yang sementara dalam proses penataan dan sudah hampir rampung. Selain kopi, objek lainnya adalah villa dan cafe. Lokasi ini juga menyediakan berbagai spot untuk mendukung kedatangan wisatawan. Suasana dan pemandangan yang sejuk dan indah membuat wisatawan tertarik berkunjung ke sana.

Tujuan penelitian ini adalah menganalisis kelayakan usaha dari Ghitari Coffee Plantation sebagai sebuah kawasan agrowisata dari aspek biofisik, ekonomi dan sosial. Hal ini penting agar tidak terjadi pemborosan terhadap penggunaan sumber daya dan sumber dana yang terbatas guna melihat apakah proyek bisnis yang akan dilaksanakan menguntungkan atau tidak (Sunyoto, 2014).

\section{Metode Penelitian}

Penelitian ini dilaksanakan pada unit Ghitari Coffe Plantation yang berlokasi di Lembang Kaero, Kecamatan Sangalla', Kabupaten Tana Toraja, Provinsi Sulawesi Selatan. Pemilihan lokasi secara purposive sampling (sengaja) dengan pertimbangan Ghitari Coffee Plantation merupakan salah satu objek agrowisata kebun pelestarian kopi arabika yang memiliki berbagai spot dan pemandangan serta suasana yang asri dan sejuk yang menarik bagi wisatawan sehingga berpotensi untuk dikembangkan. Penelitian dilaksanakan pada April- Mei 2019.

Penentuan responden menggunakan teknik purposive sampling dan accidental sampling. Purposive sampling adalah penentuan sampel berdasarkan pertimbangan tertentu, sedangkan accidental sampling adalah pemilihan sampel dari siapa saja yang kebetulan ditemui dan memiliki kesesuaian dengan tujuan penelitian. Responden dan informan dipilih dengan pertimbangan bahwa mereka adalah pihak-pihak yang mengetahui informasi dan terlibat dalam kegiatan usaha kebun pelestarian kopi arabika Ghitari Coffee Plantation.

Data primer diperoleh secara langsung dengan cara wawancara kepada pemilik usaha Ghitari Coffee Plantation dan pihak-pihak yang terkait dengan usaha 
tersebut, terutama masyarakat sekitar. Data sekunder diperoleh dari badan pusat statistik, laporan hasil penelitian perguruan tinggi dan lembaga penelitian serta sumber kepustakaan lainnya, dan media internet.

Penelitian ini menggunakan teknik analisis deskriptif kualitatif dan kuantitatif. Analisis deskriptif kualitatif digunakan untuk mengetahui tingkat kelayakan Ghitari Coffee Plantation dari aspek biofisik dan aspek sosial budaya. Analisis deskriptif kuantitatif digunakan untuk mengetahui tingkat kelayakan usaha Ghitari Coffee Plantation dari aspek ekonomi.

Aspek biofisik merupakan aspek untuk menilai/melihat penentuan lokasi, penentuan produk dan kapasitas produksi, penentuan layout dan penggunaan teknologi serta manajemen sumber daya manusia dalam mengembangkan usaha Ghitari Coffee Plantation. Ada 5 langkah yang perlu dilakukan untuk menilai kelayakan investasi ditinjau dari aspek manajemen sumber daya manusia, yaitu: perencanaan (planning), pengorganisasian (organizing), penyusunan personalia (staffing), pengarahan (leading), dan pengendalian (controlling).

Aspek sosial budaya merupakan aspek untuk melihat dampak yang ditimbulkan pariwisata terhadap kehidupan sosial dan budaya masyarakat sekitar. Dampak sosial dan budaya tersebut dilihat pada kehidupan masyarakat di Lembang Kaero.

Aspek ekonomi dianalisis berbasis data yang diperoleh dari hasil pengukuran variabel kuantitatif yakni variabel yang nilainya dapat dinyatakan secara kuantitatif atau angka. Data kuantitatif disebut sebagai data yang mengacu atau diekspresikan oleh variabel rasio dan interval (Silalahi, 2009). Analisis deskriptif kuantitatif digunakan untuk mengetahui tingkat kelayakan usaha Ghitari Coffee Plantation dari aspek ekonominya.

Dalam menganalisa aspek keuangan untuk menilai kelayakan investasi, digunakan metode NPV dan IRR. Langkah-langkah untuk menghitung NPV dan IRR adalah sebagai berikut:

a. Mengetahui jumlah kebutuhan dana untuk investasi, yaitu dengan cara membuat rencana yang terperinci dan dengan spesifikasi yang lengkap mengenai kebutuhan dana untuk investasi awal pada aktiva tetap berwujud dan aktiva tidak berwujud.

b. Menghitung jumlah aliran kas masuk bersih selama 5 tahun yaitu dengan cara: 1) menghitung proyeksi total pendapatan, yaitu dengan mengestimasi pendapatan perhari, perbulan, dan pertahun; 2) menghitung total biaya operasional, yaitu dengan mengestimasi biaya produksi perbulan dan pertahun; 3) menghitung total biaya depresiasi, yaitu dengan cara membagi biaya investasi dengan umur ekonomis usaha.

c. Menghitung NPV dan IRR dengan cara (Sunyoto, 2014):

NPV $=$ PVAKB - PVI

dimana: PVAKB $=A K B\left(\frac{1}{(1+\mathrm{i})^{\mathrm{n}}}\right)$

Keterangan :

PVAKB $=$ Present Value Arus Kas Bersih

$\mathrm{AKB}=$ Arus Kas Bersih (laba bersih + penyusutan)

$\mathrm{i}=$ tingkat suku bunga

$\left(\frac{1}{(1+i)^{n}}\right)=$ discount factor $(D F)$ 


$$
\begin{aligned}
\mathrm{n} \quad & =\text { banyak periode (tahun) } \\
\text { Atau NPV } & =-A_{0}+\sum_{t=1}^{\mathrm{n}} \frac{A t}{(1+r)^{t}}
\end{aligned}
$$

Keterangan :

Ao $=$ Pengeluaran investasi pada tahun ke- 0

At $=$ Aliran kas masuk bersih pada tahun ke-t

$\mathrm{r}=$ Tingkat keuntungan yang diisyaratkan oleh para pemilik modal

dan cara menghitung IRR yaitu:

$$
\begin{aligned}
& \text { IRR }=\frac{\text { Laba Usaha }}{\text { Modal Sendiri }} \times 100 \% \\
& \text { Atau }: \text { IRR }=i 1+\left(\frac{\text { NPV } 1}{\text { NPV1-NPV2 }}\right)(i 2-i 1)
\end{aligned}
$$

Dimana: $i 1=$ tingkat bunga pertama dan $i 2=$ tingkat bunga kedua.

\section{Hasil dan Pembahasan}

\subsection{Aspek Biofisik}

Pemilihan Lokasi. Pertimbangan pemilihan lokasi Ghitari Coffee Plantation adalah posisinya yang berada di daerah bukit dan dinilai cocok untuk budidaya tanaman kopi. Lokasi ini dapat dijangkau pengunjung dengan menggunakan motor ataupun mobil. Suasananya tenang dan jauh dari suara bising kendaraan bermotor. Udaranya sejuk dengan pemandangan alam yang indah menjadikan tempat ini cocok untuk mencari inspirasi. Jaraknya tempuh dari Kota Makale hanya sekitar 45 menit, sehingga untuk mendapatkan bahan baku untuk kegiatan produksi juga tidak terlalu sulit.

Penilaian pengunjung mengenai aksesbilitas dan sarana prasarana suatu objek wisata sangat penting untuk mengetahui tingkat kepuasan pengunjung akan produk yang ditawarkan. Aksesbilitas berupa jalan menuju objek wisata Ghitari Coffee Plantation dinilai masih kurang baik. Kondisi jalan menanjak berbahan beton yang sudah berlubang dan berbatu-batu membuat pengunjung terutama yang menggunakan sepeda motor agak kesulitan untuk melewatinya. Karena jalannya sempit maka belum bisa dilewati kendaraan roda empat seperti bus sehingga pengunjung yang datang dengan bus harus turun di jalan poros kemudian melanjutkan dengan berjalan kaki, atau menggunakan mobil milik Ghitari Coffee Plantation yang sering melewati jalan tersebut. Pengunjung berharap akses jalan desa menuju Ghitari Coffee Plantation bisa segera diperbaiki agar memudahkan wisatawan.

Penentuan Kapasitas Produksi. Dalam proses produksi, usaha ini memiliki daya tampung 7 gazebo, dimana 3 gazebo dengan kapasitas masing-masing meja dengan 8 kursi dan 4 gazebo berkapasitas meja dengan 4 kursi, berarti dapat menampung 40 pengunjung dalam sehari. Dalam operasionalnya, pekerjaan ditangani oleh 3 orang pelayan, 3 orang koki, dan 1 orang penjaga loket, serta 1 orang yang mengawasi jalannya proses produksi. Ghitari Coffee Plantation buka pada hari Senin-Jumat pukul 09.00-16.00 WITA, hari Sabtu pukul 09.00-19.00 WITA, dan hari Minggu pukul 12.0009.00 WITA. Adapun gazebo dan penginapan dibangun ditengah-tengah lahan dan sekelilingnya merupakan perkebunan kopi. 
Desain Produk dan Jasa. Jenis produk yang ditawarkan berupa jasa pariwisata alam perkebunan kopi, penginapan, cafe dan restoran. Pariwisata perkebunan kopi ditujukan agar pengunjung dapat merasakan pengalaman melakukan budidaya tanaman kopi mulai dari penyemaian hingga pembuatan kopi arabika asli Toraja yang siap diminum. Pengembangan produk atau strategi yang dilakukan yaitu dengan penataan ruang sehingga teratur dan terlihat rapi, indah dan menarik bagi wisatawan. Hal ini dilakukan untuk membedakan Ghitari Coffee Plantation dari objek wisata serupa dan agar pengunjung tidak merasa jenuh sehingga merasa puas dan tertarik untuk kembali berkunjung.

Sarana dan prasarana di Ghitari Coffee Plantation dinilai sangat baik namun pengunjung berharap agar pengelola melakukan perbaikan agar lebih menarik lagi. Letak parkiran yang jauh dan tidak ada penjaganya dirasa kurang aman untuk meninggalkan kendaraan. Pengunjung juga berharap disediakan stop kontak/terminal listrik untuk mengisi daya telepon seluler serta disediakan wifi. Namun sejauh ini pengunjung sudah merasa sangat puas dengan apa yang tersedia di Ghitari Coffee Plantation. Kondisi lokasi yang bersih, pemandangan alam yang menarik, dan pelayanan yang didapatkan membuat pengunjung ingin kembali lagi untuk berkunjung.

Penentuan Layout Usaha. Perkebunan kopi terletak di sekeliling lahan yang bentuknya memanjang terbagi kedalam 6 blok dan diberi nomor urut blok 1 sampai blok 6. Blok 1-3 terletak di sebelah barat dan blok 4-6 terletak di sebelah utara. Karena bentuk lahan yang berbukit maka dibuat terasering agar humus tidak terbawa air saat hujan. Kondisi perkebunan yang terbuka membuat tanaman kopi selalu terkena paparan sinar matahari sehingga tidak tumbuh dengan baik, oleh karenanya saat ini pengelola sedang melakukan penanaman beberapa jenis tanaman pelindung yang berfungsi sebagai penaungan bagi tanaman kopi. Peternakan unggas berada di kebun kopi blok nomor 3 dimana dalam peternakan tersebut terdapat sekitar 100 ekor unggas seperti ayam kalkun, ayam hutan, bebek dan beberapa jenis unggas yang lainnya.

Manajemen Sumber Daya Manusia. Pada tahap perencanaan dilakukan perekrutan sumber daya manusia dengan kriteria rajin, jujur dan pekerja keras. Pendidikan formal tenaga kerja umumnya tidak terlalu diperhatikan, namun ada beberapa posisi yang menetapkan pendidikan formal sebagai syarat yakni pengelola dengan pendidikan minimal SMK. Rekrutmen hanya untuk masyarakat sekitar lokasi perusahaan dan tidak dilakukan secara luas. Informasi mengenai lowongan hanya dari mulut ke mulut dan dipanggil langsung oleh pekerja yang telah ada di perusahaan, sehingga tenaga kerja yang ada dalam perusahaan umumnya masih memiliki hubungan saudara.

Saat ini tenaga kerja yang dimiliki perusahaan sebanyak 11 orang, dengan pembagian kerja 6 orang tenaga dapur yang bertugas sebagai koki yang menyediakan makanan di Cafe di dalam lokasi wisata. Selain itu terdapat 4 orang karyawan yang bertugas sebagai pelayan dan 1 orang bertugas sebagai penjaga loket. Selain itu, terdapat 1 orang tenaga kerja yang bertugas sebagai pengelola sekaligus penanggung jawab perusaahaan jika pemilik perusahaaan tidak berada di lokasi. Tugas membersihkan dilakukan oleh pelayan maupun pengelola tanpa ketentuan jam dan peraturan. 
Struktur organisasi yang digunakan Ghitari Coffee Plantation adalah struktur organisasi garis, tujuannya agar komunikasi antar pemilik usaha, manajer dan karyawan dapat berjalan dengan lancar dan pada akhirnya tujuan dapat tercapai. Struktur organisasi Ghitari Coffee Plantation dapat dilihat pada gambar berikut.

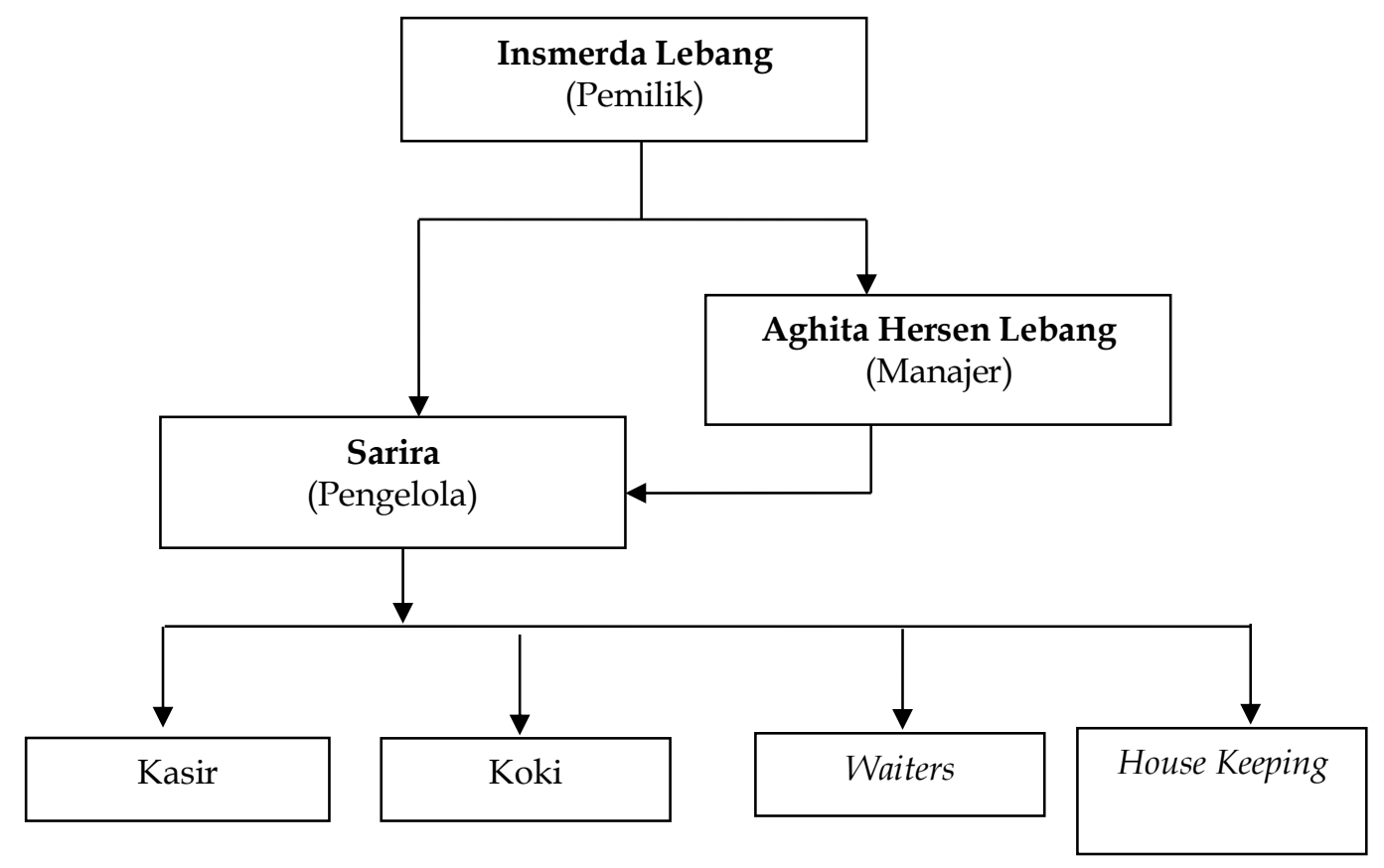

Gambar 1

Struktur Organisasi Ghitari Coffee Plantation

Pelayanan yang diberikan merupakan suatu nilai tambah dalam menilai kelayakan suatu usaha. Menurut pengunjung, pelayanan di Ghitari Coffe Plantation sangat memuaskan. Pelayanan yang baik, ramah dan sopan serta bersih membuat pengunjung merasa nyaman. Namun dalam hal menunggu pesanan makanan atau minuman menurut pengunjung memakan waktu yang cukup lama. Hal ini dikarenakan makanan atau minuman yang dipesan baru dibuat/dimasak pada saat daftar pesanan masuk ke bagian dapur. Jadi tidak ada persediaan makanan yang dimasak terlebih dahulu sebelum ada pemesanan sehingga makanan/minuman yang disajikan masih hangat dan segar.

\subsection{Aspek Ekonomi}

Sumber dana yang dimiliki oleh Ghitari Coffee Plantation merupakan modal sendiri atau berupa dana swakelola atau swadaya. Adapun untuk meninjau aspek ekonomi digunakan metode NPV dan IRR. Oleh karena itu perlu diketahui seberapa besar dana yang diperlukan, perkiraan biaya-biaya serta perkiraan pendapatan yang akan diperoleh selama 5 tahun dihitung dari tahun 0 hingga tahun ke 5. Dana yang diperlukan untuk pendirian Ghitari Coffee Plantation dapat dikategorikan ke dalam 2 bentuk dana yaitu dana untuk investasi dan dana untuk modal kerja. Dalam hal ini dana yang digunakan merupakan modal sendiri tanpa pinjaman dari pihak lain. Besarnya dana yang diperlukan dapat dilihat pada Tabel 1. 
Tabel 1

Kebutuhan Dana untuk pendirian usaha Ghitari Coffee Plantation

\begin{tabular}{lr}
\hline \multicolumn{1}{c}{ Keterangan } & Jumlah (Rp) \\
\hline Perkiraan Dana Investasi & $300.000 .000,00$ \\
Tanah & $200.000 .000,00$ \\
Gedung & - \\
Mesin & $100.000 .000,00$ \\
Peralatan & \\
Modal kerja selama 1 bulan & $5.000 .000,00$ \\
Biaya Bahan Baku & $10.000 .000,00$ \\
Biaya Gaji & $1.000 .000,00$ \\
Biaya Air, Listrik dan Telepon & - \\
Biaya Promosi & - \\
Biaya lain-lain & $620.000 .000,00$ \\
\hline Kebutuhan Dana: Investasi+Modal Kerja
\end{tabular}

Estimasi Pendapatan. Untuk membuat estimasi pendapatan perlu diketahui terlebih dahulu jumlah konsumen/wisatawan yang akan berkunjung setiap harinya. Dengan waktu efektif atau jam buka selama 9 jam perharinya dibagi 3 jam lamanya pengunjung berada di Ghitari Coffee Plantation, maka didapatkan 3 shift pergantian pengunjung setiap harinya. Dengan kapasitas 7 gazebo yang masing-masing terdapat sebuah meja dan kursi diperkirakan terdapat minimal 2-3 orang per gazebo dalam setiap shiftnya, sehingga diperkirakan pengunjung yang datang setiap harinya adalah sebanyak 42-50 orang. Jumlah ini sesuai dengan estimasi yang dipaparkan oleh Bapak Insmerda yakni sebanyak 40-50 pengunjung perhari.

Tabel 2

Estimasi Perhitungan Pendapatan Ghitari Coffee Plantation selama 5 Tahun (20182022)

\begin{tabular}{cc}
\hline Tahun & Penjualan (Rp) \\
\hline 2018 & 176.003 .000 \\
2019 & 501.674 .000 \\
2020 & 576.925 .100 \\
2021 & 663.463 .865 \\
2022 & 762.983 .445 \\
\hline
\end{tabular}

Setelah mengetahui jumlah pengunjung maka dapat diperkirakan penjualan tiket masuk perharinya sebesar Rp. 200.000 dan penjualan tiket masuk museum Rp. 200.000. Perkiraan pendapatan penjualan minuman sebesar Rp. 600.000 dan perkiraan penjualan makanan sebesar Rp. 1.000.000. Dari estimasi tersebut didapatkan estimasi total pendapatan perhari yaitu Rp. 2.000.000. Perkiraan pendapatan perbulannya adalah sebesar Rp. 60.000.000. Ghitari Coffee Plantation telah berjalan 1 tahun lebih. Dari laporan keuangan usaha, jumlah pemasukan Ghitari Coffee Plantation tertanggal 31 Desember 2018 adalah Rp. 176.003.000. Jumlah 
pemasukan tahun 2019 selama 6 bulan yakni Januari-Juni adalah sebesar Rp 105.674.000. Pemberlakuan tiket masuk baru dimulai sejak bulan Mei 2019. Pendapatan 3 tahun kedepan diharapkan akan mengalami peningkatan sebesar 15\% pertahun sehingga estimasi hasil perhitungan pendapatan dapat dilihat pada Tabel 2 diatas.

Estimasi Biaya. Kebutuhan bahan baku makanan dan minuman yang dijual di restoran diperkiraan akan meningkat setiap tahunnya seiring dengan meningkatnya jumlah pengunjung perharinya. Pembelian bahan baku makanan dan minuman dilakukan setiap minggu. Besarnya biaya bahan baku dari tahun 2018 hingga 2022 dapat dilihat pada Tabel 3.

Tabel 3

Biaya Bahan Baku Makanan dan Minuman dari Tahun 2018 hingga Tahun 2022 (dalam satuan rupiah)

\begin{tabular}{lccccc}
\hline \multirow{2}{*}{ Keterangan } & \multicolumn{5}{c}{ Tahun } \\
\cline { 2 - 6 } & $\mathbf{2 0 1 8}$ & $\mathbf{2 0 1 9}$ & $\mathbf{2 0 2 0}$ & $\mathbf{2 0 2 1}$ & \multicolumn{2}{c}{$\mathbf{2 0 2 2}$} \\
\hline Bahan makanan & 40.000 .000 & 44.000 .000 & 48.400 .000 & 53.240 .000 & 58.564 .000 \\
Bahan minuman & 35.000 .000 & 38.500 .000 & 42.350 .000 & 46.585 .000 & 51.243 .500 \\
\hline Total & $\mathbf{7 5 . 0 0 0 . 0 0 0}$ & $\mathbf{8 2 . 5 0 0 . 0 0 0}$ & $\mathbf{9 0 . 7 5 0 . 0 0 0}$ & $\mathbf{9 9 . 8 2 5 . 0 0 0}$ & $\mathbf{1 0 9 . 8 0 7 . 5 0 0}$ \\
\hline
\end{tabular}

Selain biaya tersebut juga terdapat biaya non-operasional yang berupa biaya gaji, biaya listrik dan lain-lain. Biaya pemasaran berupa promosi tidak ada. Mengenai biaya gaji karyawan tidak disebutkan secara spesifik, namun jumlah keseluruhan yang digunakan untuk membayar gaji karyawan adalah sebesar $\mathrm{Rp}$ 10.000.000 perbulannya. Biaya listrik yang dikeluarkan senilai Rp. 1.000.000 perbulan, sedangkan biaya lain-lain untuk kebutuhan mendesak sebesar Rp. 6.000.000 perbulan.

Mengenai biaya depresiasi, perhitungan depresiasi dalam penelitian ini memakai metode garis lurus. Aktiva yang mengalami depresiasi adalah peralatan dan perlengkapan usaha Ghitari Coffee Plantation dan setelah 5 tahun ditaksir tidak memiliki nilai residu. Besarnya biaya depresiasi setiap tahun mulai dari tahun 2018 sampai dengan tahun 2022 dapat dilihat pada Tabel 4.

Tabel 4

Biaya Depresiasi Ghitari Coffee Plantation Tahun 2018-2022 (dalam satuan Rupiah)

\begin{tabular}{cc}
\hline Tahun & Biaya Depresiasi (Rp) \\
\hline 2018 & 4.762 .000 \\
2019 & 4.762 .000 \\
2020 & 4.762 .000 \\
2021 & 4.762 .000 \\
2022 & 4.762 .000 \\
\hline
\end{tabular}


Berdasarkan data penjualan serta biaya-biaya diatas, langkah selanjutnya adalah membuat proyeksi perkiraan rugi/laba tahun 2018 hingga tahun 2022. Perkiraan rugi/laba penjualan dapat dilihat pada Tabel 5.

Tabel 5

Proyeksi Rugi Laba Ghitari Coffee Plantation Tahun 2018-2022 (dalam satuan rupiah)

\begin{tabular}{lrrrrr}
\hline \multicolumn{1}{c}{ Keterangan } & \multicolumn{5}{c}{ Tahun } \\
\cline { 2 - 6 } & \multicolumn{1}{c}{$\mathbf{2 0 1 8}$} & \multicolumn{1}{c}{$\mathbf{2 0 1 9}$} & \multicolumn{1}{c}{$\mathbf{2 0 2 0}$} & \multicolumn{1}{c}{$\mathbf{2 0 2 1}$} & \multicolumn{1}{c}{$\mathbf{2 0 2 2}$} \\
\hline A. Penjualan & 176.003 .000 & 501.674 .000 & 576.925 .100 & 663.463 .865 & 762.983 .445 \\
B. Biaya-Biaya & & & & & \\
B1. Biaya & & & & & \\
operasional & & & & & \\
1. Biaya Bahan & 75.000 .000 & 82.500 .000 & 90.750 .000 & 99.825 .000 & 109.807 .500 \\
$\quad$ Baku & & & & & \\
B2. Biaya non & & & & & \\
$\quad$ operasional & 5.000 .000 & 12.500 .000 & 12.300 .000 & 12.750 .000 & 13.000 .000 \\
1. biaya listrik & - & - & & - & \\
2. biaya telepon & - & - & & - & - \\
3. biaya promosi & 31.000 .000 & 92.400 .000 & 105.600 .000 & 124.800 .000 & 151.000 .000 \\
4. biaya gaji & 6.000 .000 & 6.000 .000 & 6.000 .000 & 6.000 .000 & 6.000 .000 \\
5. biaya lain-lain & 4.762 .000 & 4.762 .000 & 4.762 .000 & $4.762 . .000$ & 4.762 .000 \\
\hline 6. depresiasi & $\mathbf{1 2 1 . 7 6 2 . 0 0 0}$ & $\mathbf{1 9 8 . 1 6 2 . 0 0 0}$ & $\mathbf{2 1 9 . 4 1 2 . 0 0 0}$ & $\mathbf{2 4 8 . 1 3 7 . 0 0 0}$ & $\mathbf{2 8 4 . 5 6 9 . 5 0 0}$ \\
\hline Total biaya (B1+B2) & $\mathbf{5 4 . 2 4 1 . 0 0 0}$ & $\mathbf{3 0 3 . 5 1 2 . 0 0 0}$ & $\mathbf{3 5 7 . 5 1 3 . 1 0 0}$ & $\mathbf{4 1 5 . 3 2 6 . 8 6 5}$ & $\mathbf{4 7 8 . 4 1 3 . 9 4 5}$ \\
\hline EBIT (A+B) & 200,000 & 200,000 & & & \\
\hline Pajak & - & - & 2.500 .000 & 2.500 .000 & 2.500 .000 \\
Pajak 5\% & - & - & 5.000 .000 & 5.000 .000 & 5.000 .000 \\
Pajak 10\% & $\mathbf{2 0 0 . 0 0 0}$ & $\mathbf{2 0 0 . 0 0 0}$ & $\mathbf{4 0 . 9 0 6 . 9 6 5}$ & $\mathbf{4 8 . 3 1 9 . 0 3 0}$ & $\mathbf{5 8 . 4 1 2 . 0 9 2}$ \\
Pajak 15\% & $\mathbf{5 4 . 0 4 1 . 0 0 0}$ & $\mathbf{3 0 3 . 3 1 2 . 0 0 0}$ & $\mathbf{3 1 1 . 3 8 6 . 1 3 5}$ & $\mathbf{3 6 0 . 5 2 7 . 8 3 5}$ & $\mathbf{4 1 4 . 1 5 1 . 8 5 3}$ \\
\hline Total Pajak & & & & & \\
\hline EAT (EBIT-Pajak) & & & & & \\
\hline
\end{tabular}

${ }^{*} E B I T=$ Earning Before Interest and Taxes

${ }^{*}$ EAT= Earning After Tax

Mengacu pada estimasi pendapatan, estimasi biaya-biaya dan perkiraan rugi laba penjualan, selanjutnya dapat dihitung aliran kas masuk bersih dengan rumus sebagai berikut: Proceeds $=E A T+$ Depresiasi. Jadi hasil perhitungan kas masuk bersih dapat dilihat pada Tabel 6. 
Tabel 6

Aliran Kas Masuk Bersih Ghitari Coffee Plantation tahun 2018-2022

(dalam satuan rupiah)

\begin{tabular}{lrrrrr}
\hline \multirow{2}{*}{ Keterangan } & \multicolumn{5}{c}{ Tahun } \\
\cline { 2 - 6 } & \multicolumn{1}{c}{2018} & \multicolumn{1}{c}{2019} & \multicolumn{1}{c}{2021} & \multicolumn{1}{c}{2022} \\
\hline Laba Bersih & & & & & \\
(EAT) & 54.041 .000 & 303.312 .000 & 311.386 .135 & 360.527 .835 & 414.151 .853 \\
Depresiasi & 4.762 .000 & 4.762 .000 & 4.762 .000 & 4.762 .000 & 4.762 .000 \\
Kas bersih & 58.803 .000 & 308.074 .000 & 316.148 .135 & 365.289 .835 & 418.913 .853 \\
\hline
\end{tabular}

Perhitungan NPV. Metode Net Present Value digunakan untuk menghitung selisih antara nilai sekarang pengeluaran dengan nilai sekarang penerimaan. Dalam perhitungan NPV pada penelitian ini, tingkat keuntungan yang disyaratkan oleh pemilik modal adalah 20\%. Besarnya NPV dapat dilihat pada Tabel 7.

Tabel 7

Perhitungan Net Present Value (dalam satuan rupiah)

\begin{tabular}{crrr}
\hline Tahun & Aliran Kas Bersih & Rate of Return & PV of Proceeds \\
\hline 2018 & $58,803,000$ & 0.833 & $48,982,899$ \\
2019 & $308,074,000$ & 0.694 & $213,803,356$ \\
2020 & $316,148,135$ & 0.578 & $182,733,622$ \\
2021 & $365,289,835$ & 0.482 & $176,069,700$ \\
2022 & $418,913,853$ & 0.402 & $168,403,369$ \\
\hline PV of Proceeds & & & $789,992,946$ \\
PV of Outlays & & & 620.000 .000 \\
NPV & & & $169,992,946$ \\
\hline
\end{tabular}

Pada Tabel 7 dapat dilihat bahwa PV of Proceeds lebih besar daripada PV of Outlays. Dengan demikian Net Present Value-nya positif. Kelebihan PV of Proceeds atas PV of Outlays adalah sebesar seratus enam puluh sembilan juta sembilan ratus sembilan puluh dua ribu sembilan ratus empat puluh enam rupiah (RP. 169.992.946). Dengan demikian usaha Ghitari Coffee Plantation layak untuk dilaksanakan dari aspek keuangan karena hasil perhitungan NPV bernilai positif.

Perhitungan IRR. Internal Rate of Return (IRR) digunakan untuk mengukur kemanfaatan modal sendiri untuk menghasilkan laba. Dalam perhitungan IRR pada penelitian ini, interest rate yang disyaratkan adalah $20 \%$. Besarnya IRR dapat dihitung sebagai berikut.

$$
\begin{aligned}
& \mathrm{IRR}=\frac{\text { Laba Usaha }}{\text { Modal Sendiri }} \times 100 \% \\
& \mathrm{IRR}=\frac{169.992 .946}{620.000 .000} \times 100 \% \\
& \mathrm{IRR}=27,4 \%
\end{aligned}
$$


Berdasarkan hasil perhitungan IRR tersebut, IRR lebih besar dibandingkan interest rate yakni 20\%, sehingga disimpulkan bahwa usaha Ghitari Coffee Plantation dinilai layak untuk dikembangkan.

\subsection{Aspek Sosial dan Budaya}

Kabupaten Tana Toraja sebagai salah satu kota wisata di Indonesia memang selalu menarik banyak wisatawan untuk berkunjung. Ragam budaya yang dimiliki oleh masyarakat Tana Toraja menjadi daya tarik para wisatawan untuk berkunjung. Selain ragam budaya yang dimiliki, Tana Toraja juga terkenal dengan keindahan alam serta kopi arabika asli Toraja yang terkenal hingga mancanegara. Hal ini yang kemudian dijadikan dasar oleh seorang pengusaha untuk membuat sebuah wisata yang dipadukan dengan keindahan alam berupa perkebunan kopi. Hadirnya Agrowisata Ghitari Coffee Plantation di lingkungan Lembang Kaero memberikan dampak positif terhadap masyarakat sekitar.

Keberadaan agrowisata Ghitari Coffee Plantation dapat memberikan pengaruh atau dampak yang dirasakan oleh masyarakat. Ditinjau dari aspek sosial budaya pada dasarnya masyarakat Lembang Kaero bukanlah masyarakat yang individual, namun kondisi lingkungan dengan jarak rumah yang saling berjauhan menyebabkan masyarakat cenderung kesulitan untuk berinteraksi setiap saat. Namun dengan hadirnya Agrowisata Ghitari Coffee Plantation, masyarakat mulai sering berinteraksi satu sama lain. Hal ini dapat dilihat dari mulai seringnya masyarakat berkumpul bersama di pos penjagaan milik agrowisata Ghitari Coffee Plantation untuk sekedar berdiskusi dan bersenda gurau. Hal ini juga terjadi karena pegawai yang bekerja sebagai penjaga pos merupakan warga sekitar. Selain itu masyarakat juga terbuka terhadap orang baru atau pengunjung dari agrowisata tersebut.

Hadirnya Agrowisata Ghitari Coffee Plantation yang baru berjalan selama 2 tahun terakhir belum terlihat mempengaruhi aspek ekonomi masyarakat Lembang Kaero, hal ini disebabkan perusahaan yang baru mulai merintis usaha. Namun dengan hadirnya Ghitari Coffee Plantation diharapkan suatu saat mampu memberikan kontribusi terhadap penyediaan lapangan kerja serta mengurangi jumlah pengangguran di lingkungan Lembang Kaero.

\section{Kesimpulan}

Berdasarkan hasil analisis data dari tiga aspek yang digunakan yakni aspek biofisik, aspek ekonomi, dan aspek sosial budaya, maka Ghitari Coffee Plantation dinilai layak untuk dikembangkan dimana kepuasan pengunjung merupakan salah satu kuncinya. Pengembangan Agrowisata Ghitari Coffee Plantation akan membawa dampak ekonomi dan sosial budaya yang positif pada masyarakat sekitar lokasi tersebut.

\section{Daftar Pustaka}

Bukhori, M., 2013. Kontribusi Sektor Pertanian Terhadap Pembangunan di Indonesia. Universitas Pembangunan Nasional Veteran. Surabaya (diakses pada tanggal 5 Desember 2018) 
Itamar, H., 2016. Strategi Pengembangan Pariwisata Di Kabupaten Tana Toraja. Makassar: Universitas Hasanuddin.

Kusmiati, A. dan D.Y.Nursamsiyah, 2015. Kelayakan Finansial Usaha Tani Kopi Arabika dan Prospek Pengembangannya di Ketinggian Sedang. Agriekonomika, 4(2): 223-235.

Makarim, I.M dan M. Baiquni, 2016. Pengelolaan Agrowisata Berbasis Masyarakat di Desa Sidomulyo, Kota Batu. Jurnal Bumi Indonesia, Vol.5, No.1.

Marhaenanto, B, D. W. Soedibyo, M. Farid, 2015. Penentuan Lama Sangrai Kopi Berdasarkan Variasi Derajat Sangrai Menggunakan Model Warna RGB pada Pengolahan Citra Digital. Jurnal Agroteknologi, Vol. 09, No. 02.

Narulita, S., R.W. Asmarantaka, S. Jahroh, 2014. Analisis Daya Saing dan Strategi Pengembangan Kopi Indonesia. Jurnal Agribisnis Indonesia, Vol 2, No 1: 6374.

Parnadi, F. dan R. Loisa, 2018. Analisis Daya Saing Ekspor Kopi Indonesia. Jurnal Manajemen Bisnis dan Kewirausahaan, Vol.2, No. 4: 52-61.

Pusat Kebijakan Perdagangan Luar Negeri. 2014. Analisis Komoditas Kopi Dan Karet Indonesia: Evaluasi Kinerja Produksi, Ekspor Dan Manfaat Keikutsertaan Dalam Asosiasi Komoditas Internasional. Jakarta: Badan Pengkajian Dan Pengembangan Kebijakan Perdagangan Kementerian Perdagangan. perpustakaan kemendag.go.id

Salman, D., 2005. Pembangunan Partisipatoris. Makassar: Program Studi Manajemen Pembangunan, Unhas.

Sunyoto, D, 2014. Studi Kelayakan Bisnis. Yogyakarta:Center for Academic Publishing Services. 
JSEP, Volume 16, No..2, Juni 2020, Halaman 199 - 212 